\title{
Bacterial Amyloid and DNA are Important Constituents of Senile Plaques: Further Evidence of the Spirochetal and Biofilm Nature of Senile Plaques
}

\author{
Judith Miklossy* \\ International Alzheimer Research Centre, Prevention Alzheimer International Foundation, \\ Martigny-Croix, Switzerland
}

Accepted 10 May 2016

\begin{abstract}
It has long been known that spirochetes form clumps or micro colonies in vitro and in vivo. Cortical spirochetal colonies in syphilitic dementia were considered as reproductive centers for spirochetes. Historic and recent data demonstrate that senile plaques in Alzheimer's disease (AD) are made up by spirochetes. Spirochetes, are able to form biofilm in vitro. Senile plaques are also reported to contain elements of biofilm constituents. We expected that A $\beta P P$ and A $\beta$ (the main components of senile plaques) also occur in pure spirochetal biofilms, and bacterial DNA (an important component of biofilm) is also present in senile plaques. Histochemical, immunohistochemical, and in situ hybridization techniques and the TUNEL assay were used to answer these questions. The results obtained demonstrate that A $\beta$ and DNA, including spirochetespecific DNA, are key components of both pure spirochetal biofilms and senile plaques in AD and confirm the biofilm nature of senile plaques. These results validate previous observations that A $\beta P P$ and/or an A $\beta P$-like amyloidogenic protein are an integral part of spirochetes, and indicate that bacterial and host derived $A \beta$ are both constituents of senile plaques. DNA fragmentation in senile plaques further confirms their bacterial nature and provides biochemical evidence for spirochetal cell death. Spirochetes evade host defenses, locate intracellularly, form more resistant atypical forms and notably biofilms, which contribute to sustain chronic infection and inflammation and explain the slowly progressive course of dementia in AD. To consider co-infecting microorganisms is equally important, as multi-species biofilms result in a higher resistance to treatments and a more severe dementia.
\end{abstract}

Keywords: Alzheimer's disease, amyloid, AßPP, amyloid beta, bacteria, biofilm, Borrelia burgdorferi, colonies, chronic infection, spirochetes, thioflavin $\mathrm{S}$, Treponema spirochetes

\section{INTRODUCTION}

Historic and recent observations demonstrate that senile plaques in Alzheimer's disease (AD) are aggregated masses or colonies of spirochetes identical to those formed by Treponema pallidum (T. pallidum)

\footnotetext{
${ }^{*}$ Correspondence to: Judith Miklossy, Prevention Alzheimer International Foundation, International Alzheimer Research Centre, Martigny-Croix, CP 16, 1921, Switzerland. Tel.: +41 79207 4442/27 722 0652; E-mail: judithmiklossy@bluewin.ch.
}

and Borrelia burgdorferi (B. burgdorferi) in syphilitic and Lyme dementia [1-5]. Various types of spirochetes of the order Spirochaetales [1, 4, 6, 7], including B. burgdorferi [1, 2, 8, 9] and several periodontal pathogen spirochetes (T. denticola, $T$. socranskii, T. pectinovorum, T. amylovorum, T. maltophilum, and T. medium) were detected and/or cultivated from the AD brain $[4,7,10]$. Spirochetes persist in the affected host tissues and establish chronic infection and inflammation and are directly responsible for the late or chronic manifestations of 
various spirochetoses, including Lyme disease $[2,3$, $7,11]$.

It has long been known that spirochetes form aggregated masses or colonies in vitro and in vivo. Following Steiner, the formation of cortical spirochetal colonies in general paresis is a form of resistance to adverse conditions and a source of reproduction under more favorable conditions [12]. Spirochetal colony formation of various Treponema and Borrelia species has been the subject of further investigations during the last decades [13-15]. Spirochetal colony formation also occurs in primary cell and organotypic cultures exposed to $B$. burgdorferi $[15,16]$. These in vitro formed spirochetal colonies showed morphological and biochemical similarities to senile plaques and were immunoreactive to amyloid beta $(A \beta)$, an important component of senile plaques.

Most microorganisms have the ability to form biofilms. Bacteria in biofilm are covered by a "slime"layer, which protects them from stressful environmental conditions [17-19], therefore, the cultivation and eradication of microorganisms in biofilms is more difficult [20]. Recently, Sapi and collaborators reported evidence that $B$. burgdorferi is able to form biofilms in vitro. They also observed Borrelia biofilms in skin and lymphocytoma in patients with Lyme disease [21-23]. Biofilm formation in joints in osteoarthritis was also reported [24]. In these diseases, oral spirochetes and B. burgdorferi are implicated. Recently Allen et al. [20] further confirmed that senile plaques are made up by spirochetes and reported evidence that senile plaques have characteristics of biofilms, and co-localize with $A \beta$.

Previous immunoelectron microscopy and immunohistochemical analyses showed that spirochetes express $A \beta$ protein precursor $(A \beta P P)$ or an A $\beta P P-l i k e$ protein, which suggests that amyloid is an integral part of spirochetes and contributes to amyloid deposition in AD [1]. Onishi et al. confirmed that B. burgdorferi contains amyloidogenic protein $[25,26]$. Increasing number of recent reports indeed demonstrated that amyloidogenic protein is a previously overlooked integral part of the cellular envelope of many bacteria [27-31].

The goal of the present study was to investigate whether pure B. burgdorferi biofilms formed in vitro might also contain $\mathrm{A} \beta$, the major component of senile plaques and whether senile plaques, similarly to pure Borrelia biofilms, contain DNA, an important constituent of bacterial biofilms. A panel of histochemical and immunohistochemical techniques and dark field microscopy analysis were employed to answer these questions. DNA was detected by 4', 6-diamidine-2'-phenylindole dihydrochloride (DAPI) a fluorescent dye, which selectively binds DNA [32] and in situ hybridization was used to demonstrate spirochete-specific DNA. The terminal deoxynucleotidyl transferase dUTP nick end-labeling (TUNEL) assay was also employed to show the presence of extracellular nuclear fragmentation in senile plaques.

The present results demonstrate that $A \beta$ and bacterial DNA are important constituents of pure in vitro Borrelia biofilms and those formed in senile plaques in vivo. These results are additional evidence that senile plaques are formed by spirochetal colonies and correspond to bacterial biofilms. Biofilm formation in senile plaques further sustains chronic infection and inflammation and contributes to the development of slowly progressive dementia in AD.

\section{MATERIALS AND METHODS}

\section{Cultivation of B. burgdorferi spirochetes in BSK II medium}

B. burgdorferi spirochetes strains B31 cultivated from infected ticks, and strains ADB1, ADB2, and ADB3 [1, 2] cultivated from the brains of patients with neuropathologically confirmed definite $\mathrm{AD}$ and Lyme neuroborreliosis [2] were analyzed. All spirochetes were cultivated in BSK II medium in the following way: To $500 \mathrm{ml}$ BSK medium (Sigma B 3528) containing 6\% rabbit serum (Sigma R-7136) and 7\% gelatin (Difco 0143-15-1), $6 \mathrm{mg}$ acetyl muramic acid (Sigma A 3007) and $0.2 \mathrm{~g} \mathrm{~N}$-acetyl glucosamine (Sigma A8625), Rimactan (Novartis, $420 \mu \mathrm{l}$ ) and Fosfocin (Boehringer Mannheim, $300 \mu \mathrm{l})$ were added. The spirochetes were cultivated at $32^{\circ} \mathrm{C}$. The $\mathrm{pH}$ of BSK II medium was adjusted to pH 7.

In order to enhance biofilm formation, a set of $5 \mathrm{ml}$ of cultivated B. burgdorferi spirochetes $\left(5 \times 10^{5} / \mathrm{ml}\right)$ were exposed to various harmful conditions such as osmotic, heat shock or to strong acidic and basic conditions as previously described in detail [15]. Spirochetes cultivated at $32^{\circ} \mathrm{C}$ at $\mathrm{pH} 7$ for the same periods of time were used as controls. Series of $50 \mu \mathrm{l}$ samples were used to prepare smears for histochemical and immunohistochemical investigations. Unstained and stained preparations were examined by dark field or by light microscopy. 
Autopsy brains of $A D$ and control cases used in the study

Brains of 10 clinically and neuropathologically confirmed AD cases were analyzed. In all cases, spirochetes were demonstrated in the blood, brain, and cerebrospinal fluid (CSF) $[1,2]$ and were isolated from the brain in a modified Nogouchi medium. In three AD cases, spirochetes were also cultivated from the brain in a slightly modified BarbourStonner-Kelly II (BSK II) medium [1, 2]. Molecular characterization definitely identified these spirochetes cultivated in BSK II medium as B. burgdorferi sensu stricto (strains ADB1-3) and serological analysis confirmed that these AD patients had Lyme neuroborreliosis. The brains of four cases, without any AD-type cortical changes, where spirochetes were not observed in the blood, CSF, and brain and were not cultivated from the brain, were used as controls. The postmortem delay between death and autopsy in the ten AD and four control cases varied between 6 to 16 hours.

At autopsy, fresh, unfixed brain samples were taken from the hippocampus, inferior temporal, frontal (Brodmann's area 8-9), and parietal (Brodmann's area 39) cortical areas for direct analysis, or were frozen in liquid $\mathrm{N}_{2}$ and stored at $-80^{\circ} \mathrm{C}$ prior processing.

After removing these fresh and unfixed samples, brains were fixed in $10 \%$ formalin for 1 month. From formalin fixed brains, about $2-4 \times 3 \times 0.5-1 \mathrm{~cm}$ large blocks were taken at 12 representative levels from the cerebral hemispheres, basal ganglia, thalamus, and brainstem, for routine neuropathological investigations. For the semiquantitative assessment of AD-type cortical damage, additional blocks were taken from adjacent regions of the hippocampus, entorhinal cortex, inferior temporal cortex, frontal cortex (Brodmann's area 8-9), and parietal cortex (Brodmann's area 39). Following embedding in paraffin wax, five $\mu \mathrm{m}$ thick tissue sections were cut from all blocks and were used for the histochemical and immunohistochemical analyses.

Semiquantitative analysis of the density of senile plaques and neurofibrillary tangles was performed as previously described in detail [34]. Neuropathological assessment of the severity of cortical involvement was also made following Braak and Braak criteria [33]. For the definite neuropathological diagnosis of $\mathrm{AD}$, the criteria recommended by Khachaturian [34], CERAD [35] and the National Institute on Aging (NIA) - Reagan Institute Working group were all fulfilled [36]. The $20 \mathrm{AD}$ cases fulfilled criteria for the definite diagnosis of AD. The four, age matched control brains had no AD-type changes in the brain.

For the present study, unfixed frozen and paraffin wax embedded tissue sections from the frontal, temporal, and parietal cortex were systematically analyzed. The human brains analyzed were from the University Institute of Pathology, Division of Neuropathology, Lausanne, Switzerland. The study adhered to the tenets of the Helsinki Declaration.

\section{Dark field microscopy and histochemical analyses of spirochetes}

Samples of $50 \mu$ l of cultivated B31, ADB1, and ADB2 strains of B. burgdorferi spirochetes cultivated in optimal conditions at $\mathrm{pH} 7.0$ and those exposed to harmful conditions [15] were used as wet preparation for dark field microscopy analysis. Smears of $50 \mu \mathrm{l}$ samples on glass slides of these same strains of B. burgdorferi were also stained with Warthin \& Starry and Bosma-Steiner silver impregnation techniques and with Thioflavin $\mathrm{S}$, a sensitive fluorochrome, for the detection of amyloid in senile plaques in $\mathrm{AD}$.

\section{Histochemical and immunohistochemical analyses of brain sections}

Unfixed and fixed tissue sections were stained with hematoxylin and eosin, cresyl echt violet, thioflavin S, Periodic Acid Schiff (PAS), Congo Red, as well as with the Maurer [37] and Gallyas silver techniques [38] for the visualization of AD-type changes, including senile plaques and neurofibrillary tangles. Unfixed cryostat and paraffin sections were also stained with Warthin-Starry and Bosma-Steiner silver techniques, which detect spirochetes.

For the visualization of AD-type lesions, paraffin sections were also immunostained with a monoclonal antibody to $\mathrm{A} \beta$ (DAKO, M 827, dil.1:50) and with polyclonal antibodies to tau (A0024, DakoCyto.,) and ubiquitin (Z 0458, DakoCyto).

A monoclonal antibody (Biogenesis 7263-1006 or Chemicon MAB995, dil.1 : 200) for the detection of bacterial peptidoglycan, a bacterial cell wall component of virtually all Eubacteria, including spirochetes, was also used as previously described in detail $[39,40]$.

Detection of B. burgdorferi specific antigens was also performed as described previously [2]. To demonstrate species-specific antigens unfixed brain 
sections were post-fixed in acetone and incubated in $0.1 \%$ amylase for $5 \mathrm{~min}$ at $37^{\circ} \mathrm{C}$. Monoclonal antiOspA (H5332, H3T5, Symbicom, 1:50) and antiflagellin (G 9724, H605, Symbicom, 1:50) antibodies and polyclonal antibodies B65302 R (Biodesign, 1:100) and BB-1017 (1:500) [3] were used. The specificity of these mono- and polyclonal antibodies was previously tested by western blot analysis [2].

For immunostaining, the avidin-biotin-peroxidase technique was used. Following 24,48 , or $72 \mathrm{~h}$ incubation with a primary antibody at $4{ }^{\circ} \mathrm{C}$, the sections were incubated with the appropriate secondary antibody. For monoclonal antibodies, a biotinylated $\mathrm{F}(\mathrm{ab})$ fragment of affinity isolated rabbit antimouse immunoglobulin (Dako, E413) was used. The immunoreaction was revealed by diaminobenzidine (DAB) alone, or with nickel-ammonium sulfate as previously described [41]. Immunostaining was also performed with various anti-B. burgdorferi antibodies using FITC tagged anti-mouse or anti-rabbit secondary antibody. The green fluorescence of the positive immunoreaction was analyzed with a Zeiss fluorescent microscope. Brain tissue sections of control cases without brain lesions were immune-stained in the same way. Frozen sections immunostained in the absence of the primary antibody or with an irrelevant mono- or polyclonal antibody were used as controls.

\section{DNA labeling}

The fluorochrome 4', 6-Diamidine-2'-phenylindole dihydrochloride (DAPI), was used to detect DNA. From the 10 neuropathologically confirmed AD cases, and four control cases, $7 \mu \mathrm{m}$ thick cortical sections were cut on a cryostat, postfixed with methanol for $2 \mathrm{~min}$ and stained with $3 \mu \mathrm{g} / \mathrm{ml}$ of DAPI (Boehringer, 236 276) in methanol for $15 \mathrm{~min}$ at 37C. The sections were rinsed in distilled water for $5 \mathrm{~min}$ and were mounted with gum arabic, coversliped and examined with a fluorescence microscope either in UV light, using G 365/11 excitation and LP 397 barrier filters, or using Bp 485/20 excitation and LP 520 barrier filters. Frozen sections of control cases where also stained with DAPI. In order to remove DNA, another set of sections before staining with DAPI was treated with $1 \mathrm{mg} / \mathrm{ml}$ of DNase I (Boehringer, 1284 932) diluted in PBS containing $5 \mathrm{mmol} / \mathrm{ml}$ of $\mathrm{Mg}++$, at $\mathrm{pH} 7.8$ at $37^{\circ} \mathrm{C}$ for $3 \mathrm{~h}$. The same procedure was also carried out using RNase free DNase I (Boehringer, 776785 ). In order to eliminate the possibility of an unspecific binding of the DAPI to amyloid, a set of DNase I treated sections were post-stained with thioflavin S, widely used for the demonstration of amyloid in AD [32]. Smears of strains B31, ADB1 and ADB2 of B. burgdorferi were treated and examined in the same manner.

\section{Detection of spirochete-specific DNA by in situ hybridization}

In the three $\mathrm{AD}$ cases, where $B$. burgdorferi was cultivated from the brain, B. burgdorferi specific bacterial DNA was also detected using in situ hybridization. Hybaid, OmniGene thermal cycler was used, which was equipped with a Satellite Module of In-Situ block. Paraffin sections $(5 \mu \mathrm{m})$ and frozen sections (10 or $20 \mu \mathrm{m})$ were both employed as previously described [2]. The paraffin sections were de-waxed in xylene, hydrated in $99 \%$, and $95 \%$ ethylene and rinsed in pure water $2 \times 3 \mathrm{~min}$. On both frozen and paraffin sections, endogenous peroxidase was blocked by treatment in methanol containing $3 \% \mathrm{H}_{2} \mathrm{O}_{2}$. The sections were treated with $1 \%$ hot SDS $\left(70^{\circ} \mathrm{C}\right)$ for $5 \mathrm{~min}$, with Lysozyme $(25000 \mathrm{U} / \mathrm{ml}$ in PBS, pH 5.5 at $37^{\circ} \mathrm{C}$ ) for $5 \mathrm{~min}$ and with Proteinase $\mathrm{K}(10 \mu \mathrm{g} / \mathrm{ml}$ in $50 \mathrm{mM}$ Tris-HCL, pH 7.6 at $37^{\circ} \mathrm{C}$ ) for $30 \mathrm{~min}$. Following each treatment, the sections were washed in pure water $3 \times 10 \mathrm{~min}$. The sections were post-fixed for 20 min with $1 \%$ paraformaldehyde in PBS containing $50 \mathrm{mM} \mathrm{MgCl}_{2}$, rinsed with three changes of pure water, and dried in a series of ethanol washes. The sections were incubated with a pre-hybridization solution $(1 \mu \mathrm{l} 0.5 \mathrm{M}$ Tris $\mathrm{HCl}, \mathrm{pH} 7.4,50 \mu \mathrm{l} 20-\mathrm{X}-\mathrm{SSC}, 1 \mu \mathrm{l} 0.05 \mathrm{M}$ EDTA, $100 \mu \mathrm{l}$ of $50 \%$ dextran sulfate, $250 \mu \mathrm{l}$ formamide, and $98 \mu$ l of pure water for a total volume of $500 \mu \mathrm{l})$ in the humidity chamber of the thermal cycler at $42^{\circ} \mathrm{C}$ for $1 \mathrm{~h}$. The pre-hybridization solution was then replaced by the hybridization solution containing $100 \mathrm{ng}$ of probe labeled by nick-translation with Digoxigenin (OspA gene BBB012, SN3, position 360-426); flagellin gene BBB032, WK3, position 396-425 purchased from GENSET). The nucleotide sequence of the probes was: 5'-CAA TGG ATC TGG AGT ACT TGA AGG GGT AAA AGC T-3' and 5'-AAT GCA CAT GTT ATC AAA CAA ATC TGC TTC-3', respectively. The sections were coversliped, and 10 min incubation at $100^{\circ} \mathrm{C}$ was followed by an overnight incubation at $42^{\circ} \mathrm{C}$ in the humidity chamber of Hybaid cycler. Post-hybridization washes were in an equal mixture of formamide and 2-X-SSC, $\mathrm{pH}$ 7 at $42^{\circ} \mathrm{C}$ for $2 \times 20 \mathrm{~min}$ and in $0.1-\mathrm{X}-\mathrm{SSC}, 2 \mathrm{mg}$ $\mathrm{MgCl}_{2}, 0.1 \%$ Triton-X-100 at $60^{\circ} \mathrm{C}$ for $30 \mathrm{~min}$. After a rinse in TBS $3 \times 5 \mathrm{~min}$, the sections were treated 
with a blocking solution containing normal rabbit serum diluted $1: 5,3 \%$ bovine serum albumin and $0.1 \%$ Triton-X-100 in TBS for $1 \mathrm{~h}$. For the detection of hybridization products anti-digoxigenin alkaline phosphatase or peroxidase conjugates were used. The alkaline phosphatase substrate solution or DAB were used as chromogens for the visualization of reaction products. Control sections without specific probes and sections of control patients without AD lesions were used as negative controls.

\section{TUNEL Assay}

To analyze whether in situ DNA fragmentation occurs in senile plaques, the terminal deoxynucleotidyl transferase dUTP nick endlabeling (TUNEL) assay was performed, according to the manufacturer's instructions. Paraffin and fresh cryostat sections from the frontal cortex of three $\mathrm{AD}$ cases and two controls were post-fixed with 4\% paraformaldehyde in phosphate-buffered saline (PBS) for $10 \mathrm{~min}$, followed by two washes in PBS. The paraffin sections were heated in $80 \mathrm{ml}$ TRIS buffer in a microwave oven at $800 \mathrm{~W}$ for $5 \mathrm{~min}$. On both paraffin and frozen sections the endogenous peroxidase activity was blocked with $3 \%$ hydrogen peroxide in methanol. Following $3 \times 5$ min wash with PBS, they were treated with Proteinase $\mathrm{K}$ $(20 \mu \mathrm{g} / \mathrm{ml})$ at room temperature for $15 \mathrm{~min}$. Following another rinse with PBS $(3 \times 5 \mathrm{~min})$ the sections were fixed with $4 \%$ paraformaldehyde for $5 \mathrm{~min}$ and then treated with $1 \%$ Triton in $0.1 \%$ sodium citrate on ice for $2 \mathrm{~min}$. Slides were washed again with PBS and incubated with the TUNEL reaction mixture $(45 \mu 1$ Tunel Label: Boehringer, 1767291 and $5 \mu l$ Tunel Enzyme Boehringer, 1767305). The reaction was stopped immersing the slides in $2 \times \mathrm{SSC}$ at room temperature. The nucleotide mixture contained fluorescein-iso-thio-cyanate (FITC) labeled dUTP. In order to convert the fluorescence into a visible signal with light microscopy, the sections were treated with horseradish peroxidase (HRP)-labeled anti-FITC antibody for $30 \mathrm{~min}$ at $37^{\circ} \mathrm{C}$ (Boehringer, 1426320) and then were washed three times in PBS. The enzymatic reaction was revealed using 3,3'diaminobenzidine tetrahydrochloride (DAB) for 10 min at room temperature. The sections were counterstained with hematoxylin. Sections treated the same way but with omission of TdT enzyme from the reaction mixture were used as controls. DNA fragmentation was examined directly after the TUNEL reaction using fluorescence microscopy.

\section{RESULTS}

B. burgdorferi strain B31 cultivated from infected tick and strains ADB1-3 cultivated from the brains of $\mathrm{AD}$ cases all form biofilm in vitro and show identical morphology and biochemical properties. All strains form colony-like aggregates or biofilms enclosing numerous atypical and granular spirochetal forms. Spirochetes with the usual spiral or vegetative form are frequently seen at the periphery of these pure spirochetal biofilms. The number of biofilms was higher in 4-6 week-old cultures compared to 1-weekold cultures. Similarly, the number of $B$. burgdorferi biofilms was higher in various harmful conditions compared to those cultivated in optimal condition. Figure 1 illustrates the morphology of these pure spirochetal biofilms and some of their characteristics. They can be visualized with dark field microscopy as illustrated for strains B31 (Fig. 1A) and ADB1 (Fig. 1B), respectively. These pure B. burgdorferi biofilms, similarly to senile plaques, are argyrophilic when stained with silver impregnation techniques (Fig. 1C). They also contain species-specific antigens when immunostained with various anti-B. burgdorferi antibodies. B. burgdorferi biofilm expressing outer surface protein A (OspA) is illustrated in Fig. 1C. Pure B. burgdorferi biofilms of all strains exhibited green thioflavin S fluorescence (Fig. 1E), similar to that of senile plaques (Fig. 1F). When these pure $B$. burgdorferi biofilms were immunostained with anti-A $\beta P P$ (Fig. 1G) and anti-A $\beta$ antibodies, which are routinely used for the detection of $A \beta$ in senile plaques (Fig. $1 \mathrm{H}$ ), they exhibit positive immunoreaction to both $\mathrm{A} \beta \mathrm{PP}$ and $\mathrm{A} \beta$.

DNA labeling with DAPI of smears of pure B. burgdorferi biofilms and brain cortical sections of the $10 \mathrm{AD}$ cases analyzed, in UV light, showed silver-white fluorescence of spirochetal biofilms and senile plaques. Green DNA fluorescence of pure B. burgdorferi biofilms (Fig. 2A) and senile plaques (Fig. 2B, C) are visible when Bp 485/20 excitation and LP 520 barrier filters are employed. On brain sections, in addition to fluorescent brain cell nuclei, senile plaques exhibit fluorescence of DNA as illustrated in a familial AD case (Fig. 2B) and in the $\mathrm{AD}$ case where $B$. burgdorferi strain $\mathrm{ADB} 1$ was cultivated from the brain (Fig. 2C). In the four control cases, without AD-type changes, only nuclei of brain resident cells showed fluorescence (Fig. 2D). DNase I or RNase free DNase I pretreatment abolished DNA fluorescence of both brain cell nuclei and senile plaques (Fig. 2E). When DNase treated brain 

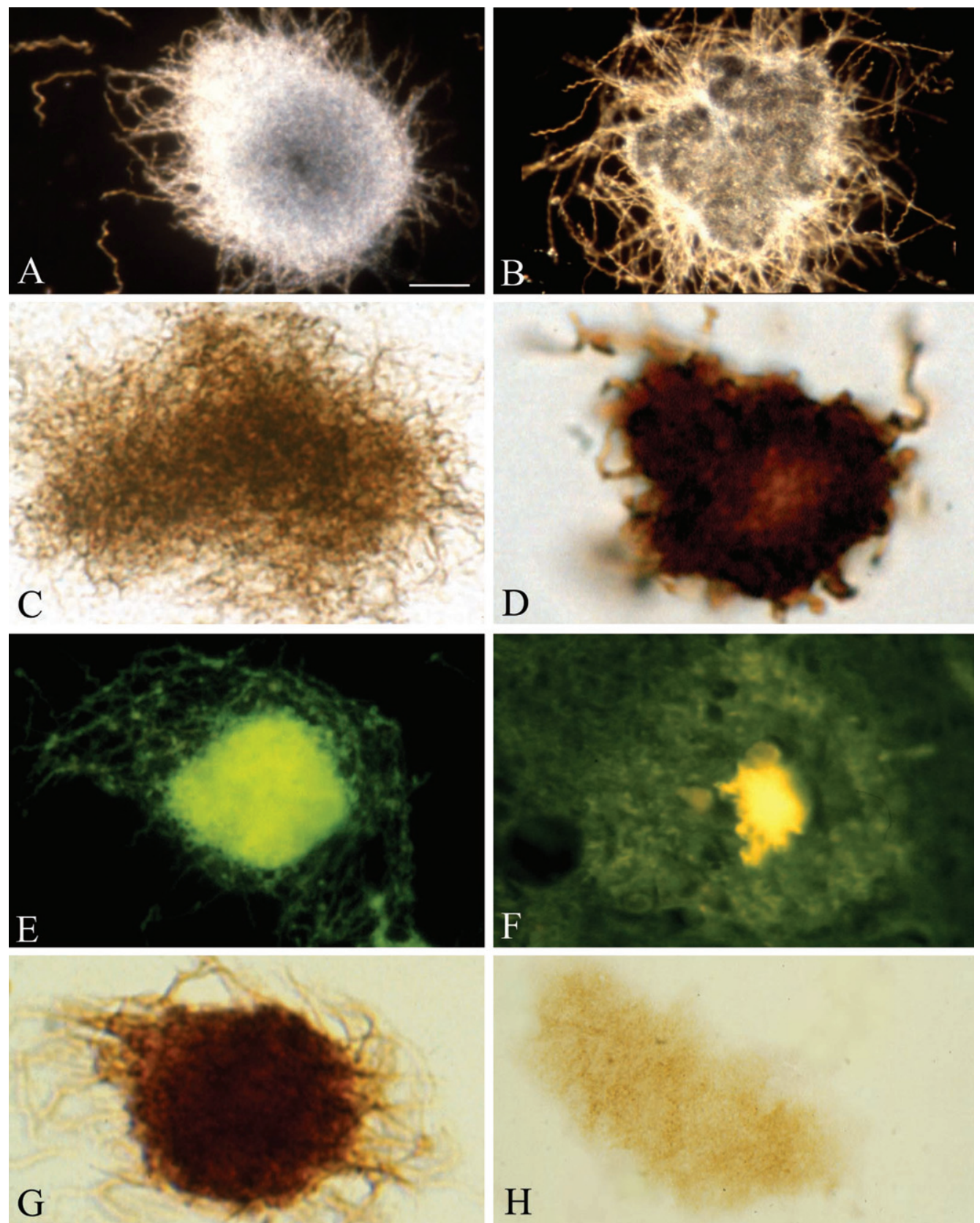

Fig. 1. Pure in vitro B. burgdorferi biofilms contain $A \beta$ an important component of senile plaques. A, B) Dark field microscopy images of pure B. burgdorferi biofilms of reference strain B31 cultivated from infected tick (A) and strain ADB1 cultivated from the brain of an AD patient with confirmed chronic Lyme neuroborreliosis (B). C) Pure B. burgdorferi biofilm of strain ADB2 stained with Warthin and Starry silver technique for the detection of spirochetes. D) Pure B. burgdorferi biofilm of strain ADB2 immunostained with anti-OspA monoclonal antibody exhibiting positive immunoreaction. E) Green thioflavin S fluorescence of in vitro formed B. burgdorferi biofilm of strain ADB2. F) Thioflavin S fluorescence of a senile plaque in the frontal cortex of an AD patient where B. burgdorferi ADB2 strain was cultivated from the brain. G) In vitro formed B. burgdorferi biofilm (strain B31) immunoexpressing A $\beta \mathrm{PP} ; \mathrm{H}$ ) In vitro B. burgdorferi biofilm of strain ADB1 exhibiting positive $A \beta$ immunoreaction. Scale bar $=A$ : $15 \mu \mathrm{m}$ for $\mathrm{A}-\mathrm{C}$ and $\mathrm{E}-\mathrm{H}$ and $10 \mu \mathrm{m}$ for $\mathrm{D}$.

sections were post-stained with thioflavin $\mathrm{S}$, senile plaques showed strong yellow-green thioflavin S fluorescence indicating that DNase I does not abolish amyloid staining (Fig. 1F). As bacteria are lacking nuclear membrane and their DNA is diffusely distributed in their cytoplasm, DNA labeling with DAPI 

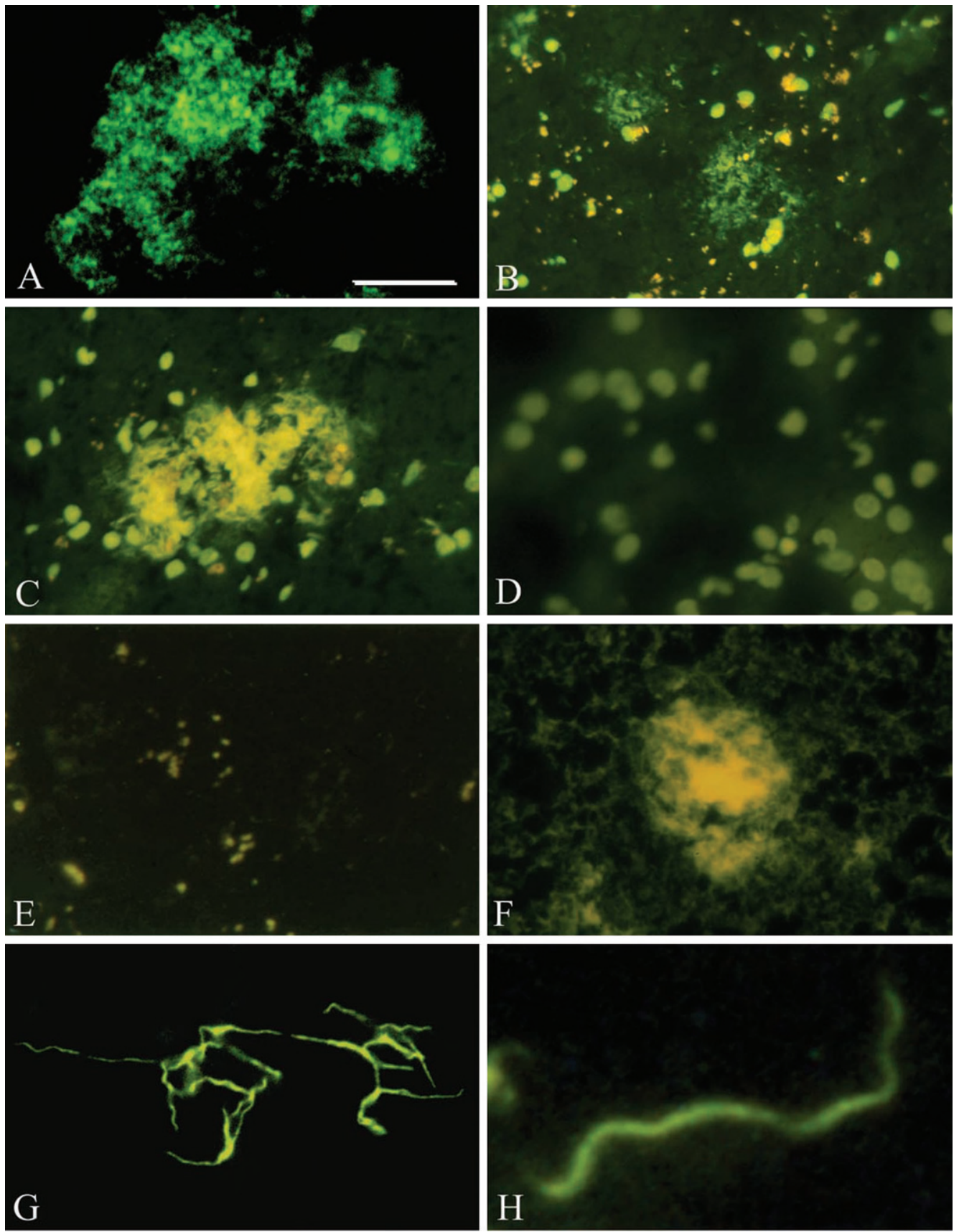

Fig. 2. Pure in vitro B. burgdorferi biofilm and senile plaques both contain DNA, an important constituent of biofilms. A) Smear of in vitro B. burgdorferi biofilm of ADB2 strain stained with DAPI and exhibiting green fluorescence, when examined with Bp 485/20 excitation and LP 397 barrier filters. Similar DAPI fluorescence of senile plaques is seen in frontal sections of a familial (B) and an AD case where $B$. burgdorferi spirochetes were cultivated from the brain (C). D) On DAPI-stained frontal section of a control case only brain cell nuclei are visible. E) Following DNase treatment of a frontal cortical section of an AD case, the DAPI fluorescence of resident cell nuclei and senile plaques both disappeared. F) DNase treated AD cortical section stained with Thioflavin S. Senile plaque exhibits a yellow-green fluorescence indicating that DNase pretreatment does not abolish amyloid staining of the plaques. G, H) DAPI fluorescence of $B$. burgdorferi spirochetes, revealing their typical helical structure. Photomicrographs E and F were reproduced from [32] with kind permission of the editor of Journal of Spirochetal and Tick-borne Diseases. Scale bar =A: $60 \mu \mathrm{m}$, B: $200 \mu \mathrm{m}, \mathrm{C}: 120 \mu \mathrm{m}, \mathrm{D}: 100 \mu \mathrm{m}, \mathrm{E}: 120 \mu \mathrm{m}, \mathrm{F}: 10 \mu \mathrm{m} ; \mathrm{H}: 2 \mu \mathrm{m}$. 

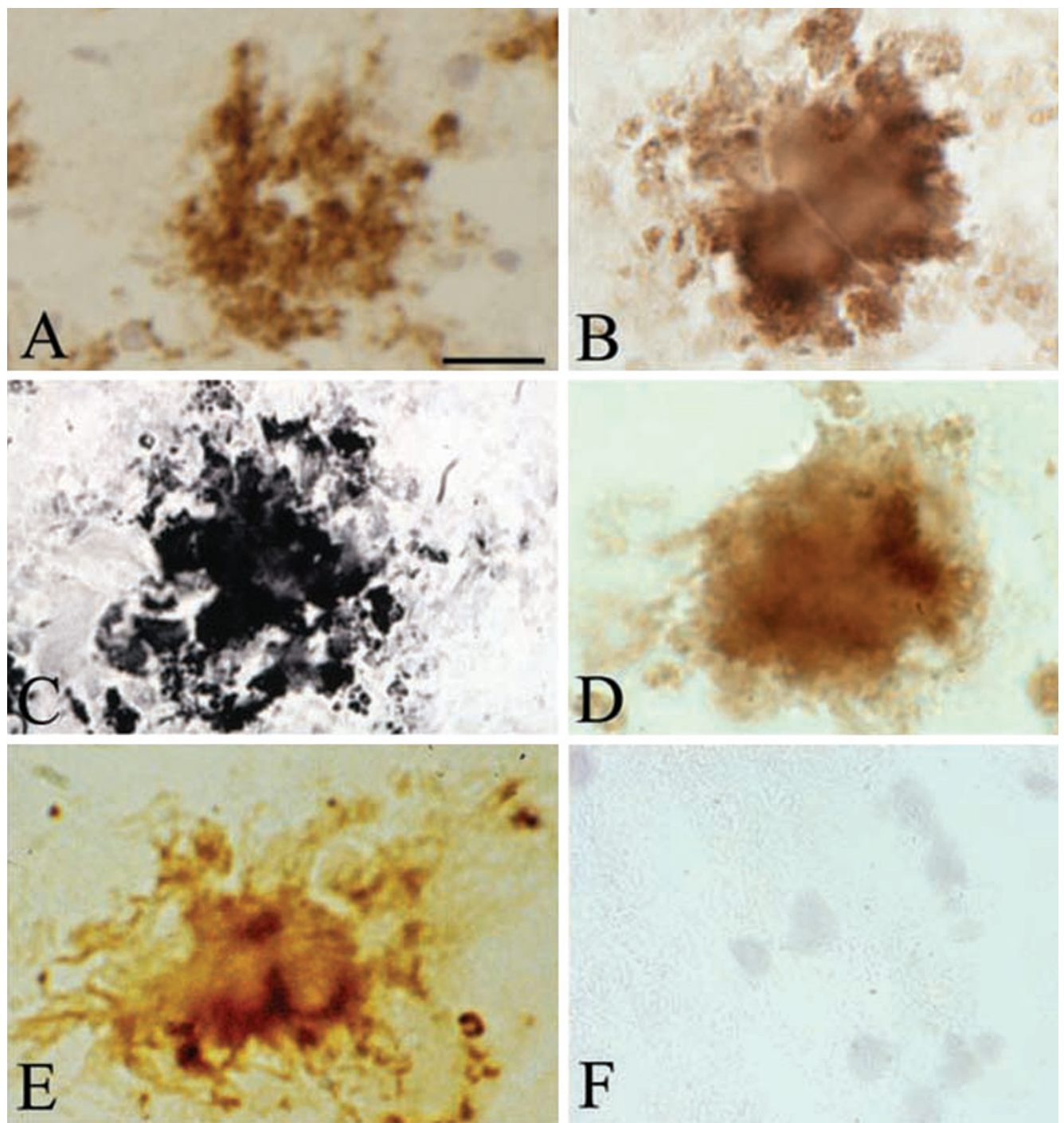

Fig. 3. Senile plaques contain spirochete-specific DNA. Photomicrographs of spirochetal colonies or biofilms in an AD case with confirmed Lyme neuroborreliosis where B. burgdorferi spirochetes (ADB1) were cultivated from the brain. A) Positive A $\beta$ immunoreaction of senile plaque. B) Senile plaque of the same AD case, as in A, exhibiting strong immunoreaction for bacterial peptidoglycan. C, D) Photomicrographs showing $B$. burgdorferi antigens in senile plaques immunostained with a polyclonal anti-B. burgdorferi antibody (C) and with a monoclonal anti-OspA antibody (D). E) B. burgdorferi specific DNA detected by in situ hybridization in senile plaque of an AD patient where ADB1 strain was cultivated. F) Cortical section of a control case immunostained with a monoclonal anti-OspA antibody showing no immunoreaction. Scale bar $=$ A-E: $40 \mu \mathrm{m}, \mathrm{F}=25 \mu \mathrm{m}$. Photomicrograph E is a reproduction of Fig. 2b of [7].

reveals their characteristic morphology. DNA florescence of a small group (Fig. 2G) and a single spirochete (Fig. 2H) when stained with DAPI demonstrates, by the diffusely located bacterial DNA, the helical shape of $B$. burgdorferi.

Immunodetection of $A \beta$ in senile plaques is routinely used for the neuropathological diagnosis of AD. When cortical sections of the $10 \mathrm{AD}$ cases analyzed, including in the three $\mathrm{AD}$ cases where B. burgdorferi were cultivated from the brain senile plaques showed strong $A \beta$ immunoreaction with all of the anti-A $\beta$ antibodies used (Fig. 3A). Senile plaques are also immonoreactive to the highly specific anti-bacterial peptidoglycan antibody (Fig. 3B). In the three $\mathrm{AD}$ cases where B. burgdorferi was also cultivated from the brain in BSK II medium (strains ADB 1-3), not only $A \beta$ and bacterial peptidoglycan but $B$. burgdorferi specific antigens are also present in senile plaques. Figure $3 \mathrm{C}$ and D illustrate the presence of $B$. burgdorferi specific antigens in senile 

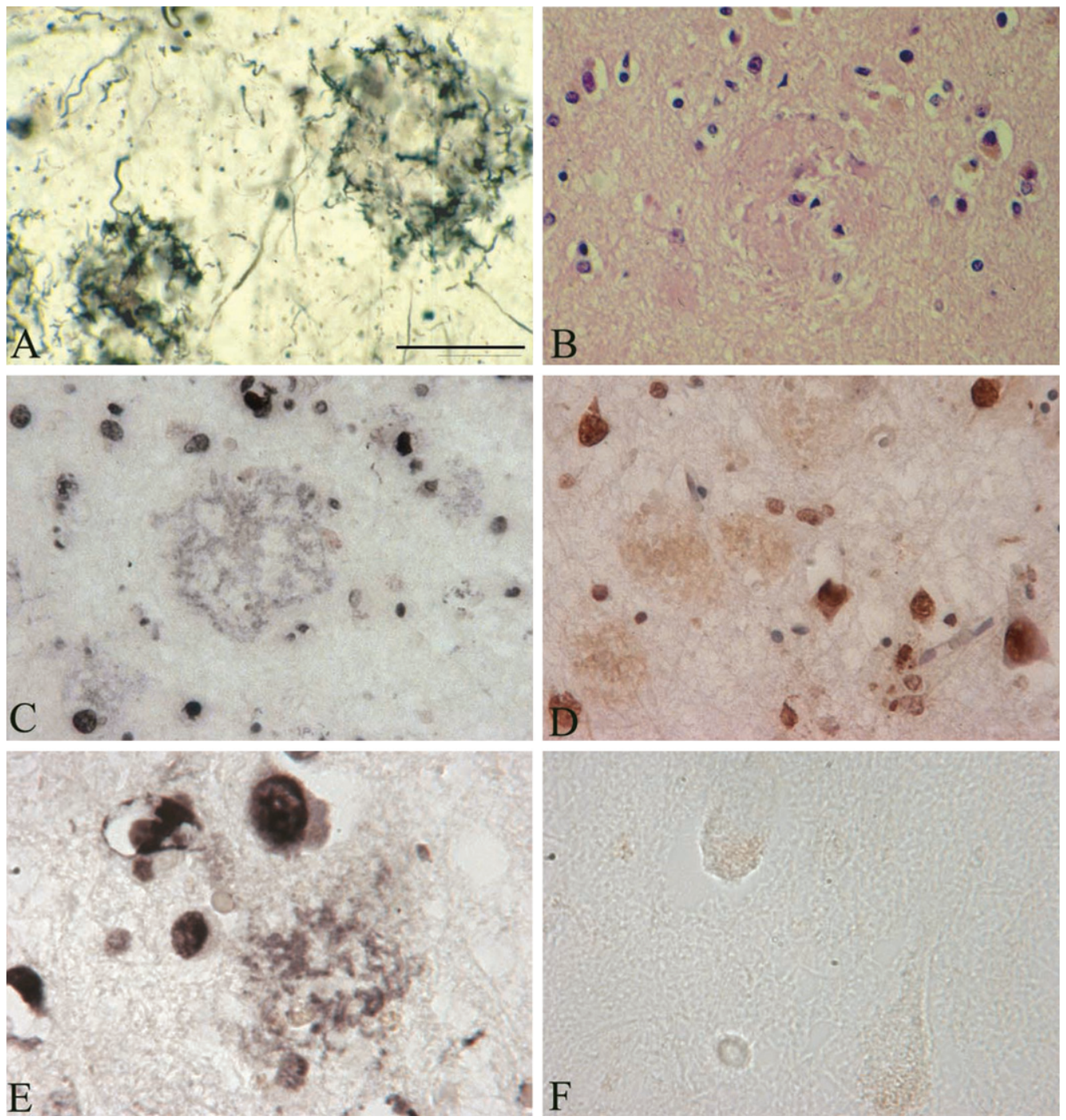

Fig. 4. In situ DNA fragmentation in senile plaques using the terminal deoxynucleotidyltransferase-mediated dUTP nick end-labeling (TUNEL) assay. A) Senile plaques in an AD case where B. burgdorferi (strain ADB1) was cultivated from the brain. Frozen section stained with Maurer technique used for the detection of senile plaques in AD. B) Paraffin section stained with Haematoxylin and eosin, in the same case as in A, showing senile plaques in the frontal cortex. C-E) Frozen (C and E) and paraffin (D) sections from the frontal associative area (Brodmann's area 8-9) of the AD case, where B. burgdorferi strain ADB2 was cultivated from the brain. The TUNEL assay demonstrates in situ DNA fragmentation in black (C and E) or in brown (D) color. The majority of cells showing apoptosis are large nuclei of neurons, but some glial cells also exhibit TUNEL positive nuclei. Scale bar =A-C: $150 \mu \mathrm{m}, \mathrm{D}: 200 \mu \mathrm{m}, \mathrm{E}, \mathrm{F}: 80 \mu \mathrm{m}$.

plaques as revealed by polyclonal and monoclonal anti-B. burgdorferi antibodies, respectively. In these three AD cases where the ADB strains were cultivated from the brain, B. burgdorferi specific DNA is demonstrated in senile plaques by in situ hybridization (Fig. 3E). The extranuclear localization of B. burgdorferi specific DNA excluded the possibility of an unspecific DNA labeling of host cell nuclei. Control sections where specific B. burgdorferi antibodies or probes were omitted were negative (Fig. 3F). Cortical sections of control cases without
AD-type changes and where spirochetes were not cultivated from the brain did not show $A \beta$ and bacterial peptidoglycan immunoreaction or B. burgdorferi specific antigens or DNA.

In the three $\mathrm{AD}$ cases analyzed, the TUNEL assay shows DNA fragmentation not only of various brain cell nuclei but in a number of senile plaques as well, in an extracellular location. Figure 4 illustrates DNA fragmentation in senile plaques as revealed by the TUNEL assay in the frontal cortex of an AD case where B. burgdorferi was cultivated from the brain. 
Silver impregnation technique [37] (Fig. 4A) and hematoxylin and eosin stain (Fig. 4B) show the presence of typical senile plaques in the frontal cortex in this AD case. DNA fragmentation in a number of brain cell nuclei, mostly in neurons, and in some glial and endothelial cells is visible. In situ DNA fragmentation as revealed by TUNEL in a subset of senile plaques located extracellularly with respect to resident brain cells is also apparent on both frozen (Fig. 4C, E) and paraffin (Fig. 4D) sections. The extracellular distribution of this DNA fragmentation, located mostly in filamentous structures is similar to the DNA detected by DAPI and to spirochete-specific DNA revealed by in situ hybridization. Only few neurons exhibited nuclear fragmentation and extracellular TUNEL reaction was not present in the brains of the two control cases analyzed.

\section{DISCUSSION}

Amyloidogenesis is the aggregation of soluble proteins into detergent-insoluble filamentous structures, which have distinct biochemical and biophysical properties, including resistance to proteinase $\mathrm{K}$ treatment, beta-sheet structure and affinity for binding thioflavin $\mathrm{S}$ and Congo red.

Recent observations indicate that aggregated masses or colonies of $B$. burgdorferi spirochetes formed in vitro have characteristics of biofilms [21]. Even more recently, Allen et al. [20] demonstrated that senile plaques, which were shown to correspond to spirochetal masses or colonies, have properties of biofilm. B. burgdorferi spirochetes also form such colonies following infection of mammalian cells or organotypic cultures in vitro [16], which exhibit $\mathrm{A} \beta$-immunoreaction and are undistinguishable from senile plaques in $\mathrm{AD}$.

We anticipated that if pure $B$. burgdorferi biofilms formed in vitro comprise $\mathrm{A} \beta \mathrm{PP}$ and $\mathrm{A} \beta$ would indicate, as previously suggested [1], that bacterial amyloid is an important component of senile plaques in AD. This would also indicate that bacterial amyloid is an important constituent of biofilms, and contribute to the formation of the slimy material covering and protecting bacteria in biofilms. Accordingly, we analyzed and compared the amyloid characteristics of in vitro formed pure spirochetal biofilms with those formed in senile plaques in vivo. Ten definite $\mathrm{AD}$ cases where spirochetes were cultivated in a modified Nogouchi medium and four control cases without AD-type changes were analyzed. In three of the 10
AD cases with clinically and neuropathologically confirmed Lyme neuroborreliosis, spirochetes were also cultivated in BSK II medium and using molecular techniques were definitely identified as B. burgdorferi sensu stricto (strains ADB1, ADB2, and ADB3) [2]. The analysis of the characteristics of these ADB Borrelia strains allowed us to directly compare the characteristics of pure in vitro Borrelia biofilms with those formed in vivo in senile plaques.

All spirochetal strains analyzed (B31 and ADB1-3) have the ability to form biofilms in vitro. Biofilms formed by these various strains have similar morphological and chemical properties. As observed by dark field microscopy and by the presence of species-specific antigens, the formation of spirochetal biofilms in vitro was enhanced in older cultures with a higher spirochetal cell density and in various harmful conditions, compared to those cultivated in optimal conditions.

Thioflavin S, which binds amyloid with high affinity, strongly binds pure $B$. burgdorferi biofilms, indicating that they contain amyloid. As A $\beta P P$ and $\mathrm{A} \beta$ are important components of senile plaques, smears of pure Borrelia biofilms of all strains were immunostained with a set of mono- and polyclonal antibodies specifically recognizing $\mathrm{A} \beta P P$ and $A \beta$. Pure biofilms of all Borrelia strains studied exhibited a positive immunoreaction, demonstrating that similarly to senile plaques pure Borrelia biofilms contain $\mathrm{A} \beta \mathrm{PP}$ and $\mathrm{A} \beta$. These results further confirm previous observations based on immunohistochemical and immunoelectronmicroscopical analyses that $\mathrm{A} \beta \mathrm{PP}$ or an A $\beta P P-l i k e$ amyloidogenic protein is an integral part of spirochetes. This indicates that bacterial amyloid contributes to $\mathrm{A} \beta$ deposition in $\mathrm{AD}$ [1]. That amyloid is an integral part of spirochetes, namely of B. burgdorferi, was further confirmed by Ohnishi et al., who reported that the $\mathrm{BH}(9-10)$ peptide on a beta-hairpin segment of B. burgdorferi OspA, forms amyloid fibrils in vitro that is similar to human amyloidosis $[25,26]$. These results are in agreement with previous observations that $B$. burgdorferi spirochetes form $\mathrm{A} \beta$ immunoreactive colonies, similar to senile plaques in vitro following infection of primary neuronal and glial cells or organotypic cultures [16]. Borrelia colonies or biofilms formed in vitro adhering to cells or free floating in the medium, both exhibited thioflavin S fluorescence and immunoexpressed $A \beta$ [16].

These results are also in agreement with the observations that the cortical spirochetal colonies of T. pallidum in syphilitic dementia are $\mathrm{A} \beta$ immunoreactive [5, 42]. 
Amyloid proteins constitute a previously overlooked integral part of the cellular envelope of many bacteria [27, 29-31]. Bacterial amyloids are biologically functional molecules, which play an important role in virulence, invasion, and host cell destruction [27-30]. Bacterial amyloids are involved in bacterial cell-cell interactions, in their attachment to inert solid surfaces, and in spore and biofilm formation [28].

All these observations indicate that bacterial amyloid is present in senile plaques.

Host cells and bacteria, during host-pathogen interactions, use similar molecular mechanisms to induce host cell lysis and bacteriolysis. Recent observations reveal that $A \beta$, the most important biological marker of $\mathrm{AD}$, is an innate immune molecule, and shares properties with antimicrobial peptides [43]. Soluble $\mathrm{A} \beta_{1-42}$ oligomers form channels on lipid cell membranes and cause $\mathrm{Ca}^{2+}$ influx and cell destruction [44]. Channel formation in the membrane of targeted host cells triggering cellular ion imbalance is also a form of bacterial attack $[45,46]$. This is also in harmony with the present findings that bacterial $A \beta$ with neurotoxic activities and host derived $A \beta$ with antimicrobial properties both are constituents of amyloid deposits in AD. Further studies will be required to distinguish between host and bacteria derived amyloid and determine whether host cell destruction predominates over bacteriolysis in chronic sustained infections and determine whether the lower level of inflammation in chronic disorders might be insufficient to clear invading pathogens.

The present observations also demonstrate that bacterial amyloids are critical components of biofilms and play an important role in biofilm formation, and in formation of the slimy cover, which confers to bacteria protection against harmful conditions and host immune reactions.

DAPI is a fluorescent dye, which binds selectively to DNA [47] and forms strongly fluorescent DNA-DAPI complexes with high specificity, yielding highly fluorescent nuclei and no detectable cytoplasmic fluorescence $[47,48]$. Its specificity was found to be similar to that of the fluorescent DNA-binding benzimidole derivative Hoechst 33258 [47, 48]. DAPI, by its specificity and sensitivity, is frequently used for the detection of Mycoplasma infection in cell cultures [47, 49]. Mitochondrial DNA binds DAPI, but at levels imperceptible by routine fluorescent microscopy [49]. Bacteria being prokaryotic cells contain DNA, but they differ from eukaryotic cells in that the nuclear material is not surrounded by a limiting nuclear membrane. We therefore expected that
DAPI binds the DNA of spirochetes as well and show their characteristic helical shape [32]. As demonstrated here, reference spirochetes by their DNA content can be visualized by DAPI [32]. If senile plaques are indeed formed by spirochetes and correspond to biofilms, they would consequently contain DNA outside resident cell nuclei and exhibit DAPI fluorescence. Here we demonstrate that DAPI indeed binds to senile plaques indicating that they contain DNA. The extracellular distribution of DNA in filamentous structures, similar to those seen in individual spirochetes, together with historic and recent observations showing that senile plaques are made up by spirochetes and correspond to biofilm indicate that the extracellular DNA in senile plaques detected by DAPI corresponds to bacterial DNA. DNA-se I treatment abolishes not only the DAPI fluorescence of host cell nuclei but that of senile plaques as well. The fact that DNase pretreatment did not abolish thioflavin $S$ fluorescence of senile plaques [32] indicates, in agreement with Russel et al. [47], the specificity of DAPI as a sensitive DNA fluorescent stain of eukaryotic and prokaryotic DNA. The present observations further indicate that spirochetes are causal agents in $\mathrm{AD}$ and in an analogous way to T. pallidum various periodontal pathogen spirochetes, B. burgdorferi, and other, still uncharacterized virulent spirochetes can cause dementia, cortical atrophy, and amyloid deposition in $\mathrm{AD}$.

In order to confirm the spirochetal origin of DNA detected in senile plaques by DAPI, specific nucleic acid probes detecting $B$. burgdorferi specific DNA were also used in AD cases with clinically, serologically, and neuropathologically confirmed Lyme neuroborreliosis where $B$. burgdorferi was cultivated from the brains. In the brains of these AD cases, B. burgdorferi-specific spirochetal DNA was demonstrated in senile plaques using in situ hybridization, indicating that the DNA detected by DAPI is indeed spirochetal DNA.

The most common mode of programmed cell death is apoptosis. Many of the morphological and biochemical responses associated with apoptosis in eukaryotes also occur in prokaryotes. One of these markers, which occurs in both, is DNA fragmentation [50-52]. DNA fragmentation of apoptotic bacterial cells similarly to those of apoptotic host cell nuclei can be demonstrated by TUNEL assay, which incorporates fluorescein-dUTP into the ends of fragmented DNA [52]. If senile plaques are indeed spirochetal biofilms, we expected that fragmentation of bacterial DNA might also be present in senile 
plaques. Using TUNEL, extracellular DNA fragmentation is present in a subset of senile plaques. The location and distribution of extracellular DNA fragmentation is identical to those of DAPI fluorescence and spirochete-specific DNA as revealed by in situ hybridization. This indicates that this extracellular DNA fragmentation in senile plaques revealed by TUNEL corresponds to bacterial apoptosis in spirochetal colonies or biofilms formed in senile plaques.

A number of resident brain cells, predominantly neurons, and to a lesser extent glial and endothelial cells also showed DNA fragmentation by TUNEL. DNA fragmentation in astrocytes is rarely seen. These results indicate that spirochetes cause functional damage and cell death in host tissues. This is in agreement with previous observations that spirochetes induce apoptosis of resident brain cells, mostly of neurons in vivo $[53,54]$. Apoptosis of neurons and glial cells was also observed following $B$. burgdorfer $i$ infection of primary mammalian cells and organotypic cultures in vitro [15].

During infection, pathogens employ a broad range of strategies to overcome antigenic recognition, phagocytosis, and complement lysis. Blockade of the complement cascade allows their survival even in immune competent hosts. If pathogens are not recognized by the host immune systems or in the absence of cell-mediated immune responses, the microorganism can spread freely and accumulate in the affected host tissues. Under such conditions, the microorganisms establish chronic infection, inflammation, and progressive tissue damage. Biofilms protect invading spirochetes from destruction by the host immune reactions and in the maintenance of chronic infection. These spirochetal agglomerations or biofilms in senile plaques in accordance with Steiner are a form of resistance to adverse conditions, and a source for newly growing spirochetes under more favorable conditions [12].

That extracellular DNA, an important component of biofilms, is also present in senile plaques indicates that senile plaques are indeed made up by spirochetes, and contain bacterial amyloid in the form of $A \beta$, and confirm recent observations [20] that senile plaques indeed correspond to biofilms. The present results further highlight that amyloid is an essential component of in vitro and in vivo formed biofilms. Microbial amyloids, through interaction with host proteases, contribute to bacterial virulence, to colonization of the host and invasion of host cells.

Evasion of spirochetes from host immune reactions initiates and sustains the proliferation of spirochetes and their aggregation leading to biofilm formation in the form of senile plaques in $\mathrm{AD}$. These results explain why dementia appears years or decades following the primary spirochetal infection and why long standing chronic bacterial infections are frequently association with amyloid deposits. They also indicate that in various chronic inflammatory disorders, which are associated with amyloidosis the involvement of bacteria should be investigated.

Reports of an association between infection and $\mathrm{AD}$ are not confined to spirochetes. Chlamydia pneumonia. Porphyromonas gingivalis, Proprionobacterium acne, Helicobacter pylori and other bacteria were also found to be associated with $\mathrm{AD}$ [55-61] and mice exposed to Chlamydia pneumoniae developed AD-like amyloid plaques in the brain [62]. Herpes virus type 1 and other viruses were also demonstrated in the brain in $\mathrm{AD}[64,65]$. As spirochetes frequently co-infect with other bacteria and various viruses to consider that senile plaques may correspond to multimicrobial biofilms is important.

\section{CONCLUSION}

Biofilm formation confers to bacterial resistance to antibiotics and other anti-microbial agents and contributes to the establishment of chronic infection. Recently it was demonstrated that spirochetes are able to form biofilms in vitro and senile plaques have characteristics of biofilm.

If senile plaques indeed correspond to biofilms, bacterial amyloid and DNA should be the component of both pure spirochetal biofilms formed in vitro and biofilms in senile plaques formed in vivo. Ten definite $\mathrm{AD}$ cases and four controls without $\mathrm{AD}$ type changes were analyzed. Three AD cases with clinically and neuropathologically confirmed Lyme neuroborreliosis, where $B$. burgdorferi spirochetes were cultivated from the brain and were definitely identified as $B$. burgdorferi sensu stricto, enabled us to compare pure $B$. burgdorferi biofilms formed in vitro with $B$. burgdorferi biofilms formed in senile plaques in $\mathrm{AD}$ in vivo.

The present results reveal that $A \beta P P$ and $A \beta$ are not only important components of senile plaques but of pure in vitro formed B. burgdorferi biofilms as well, indicating that bacterial amyloid together with host derived $A \beta$ are important constituents of senile plaques and support previous observations that $\mathrm{A} \beta \mathrm{PP}$ or an A $\beta P P-l i k e$ amyloidogenic protein is an integral part of spirochetes and contribute to amyloid 
deposition in $\mathrm{AD}[1]$. The results also indicate that the known physical and chemical properties of amyloid strongly contribute to the protective effect of biofilms against harmful conditions and against host immune responses.

Bacterial DNA (as visualized by DAPI) and spirochete-specific DNA (as detected by in situ hybridization) are further indication that senile plaques are made up by spirochetes and correspond to biofilms. Bacterial apoptosis is also present in a subset of senile plaques and is indicative of the bacterial or biofilm nature of senile plaque and represents chemical evidence of spirochetal cell death. Nuclear fragmentation of resident cell nuclei indicates that spirochetes, including B. burgdorferi cause DNA fragmentation of neuronal, glial, and endothelial cells in AD.

The present findings strengthen previous observations that $\mathrm{A} \beta \mathrm{PP}$ or an $\mathrm{A} \beta \mathrm{PP}-$ like amyloidogenic protein is an integral part of spirochetes, and contribute to $\mathrm{A} \beta$ deposition in $\mathrm{AD}$.

These observations also highlight the direct role of B. burgdorferi and other spirochetes in the chronic manifestations of neurospirochetoses, and indicate that spirochetes play a causal role in $\mathrm{AD}$ and in Lyme dementia.

Spirochetal biofilms in senile plaques strongly contribute to the long latent stage and to persisting infection in chronic neurospirochetoses, including in Lyme disease. The ability of spirochetes to evade host defenses, the formation of bacterial biofilms in senile plaques, together with the ability of spirochetes to locate intracellularly and form more resistant atypical forms all contribute to establish and sustain chronic infection and inflammation and lead to progressive dementia, sometimes decades following the primary infection.

As targeted therapies are available, it is imperative to stop and prevent, as early as possible, the devastating consequences of various chronic spirochetoses, including Lyme disease and periodontal disorders.

\section{ACKNOWLEDGMENTS}

MJ initiated the work and contributed to the conception, design, analysis, and reproduction of the data. She wrote the manuscript, prepared illustrations, and takes the responsibility for the accuracy and integrity of the presented work.

This work was supported by the Prevention Alzheimer International Foundation, Switzerland.
The author's disclosure is available online (http:// j-alz.com/manuscript-disclosures/16-0451r1).

\section{REFERENCES}

[1] Miklossy J (1993) Alzheimer's disease - A spirochetosis? Neuroreport 4, 841-48.

[2] Miklossy J, Khalili K, Gern L, Ericson RL, Darekar P, Bolle L, Hurlimann J, Paster BJ (2004) Borrelia burgdorferi persists in the brain in chronic Lyme neuroborreliosis and may be associated with Alzheimer disease. J Alzheimers Dis $\mathbf{6}$, 639-649.

[3] Miklossy J (2008) Biology and neuropathology of dementia in syphilis and Lyme disease. In Handbook of Clinical Neurology, Duyckaerts C, Litvan I, eds. Elsevier, Series, Aminoff MJ, Boller F, Schwab DS). Elsevier, 89, pp825844.

[4] Miklossy J (2011) Alzheimer's disease - a neurospirochetosis. Analysis of the evidence following Koch's and Hill's criteria. J Neuroinflammation $\mathbf{8}, 90$.

[5] Miklossy J (2015) Historic evidence to support a causal relationship between spirochetal infections and Alzheimer's disease. Front Aging Neurosci 7, 46.

[6] Miklossy J (2008) Chronic inflammation and amyloidogenesis in Alzheimer's disease - role of spirochetes. J Alzheimers Dis 13, 381-391.

[7] Miklossy J (2011) Emerging roles of pathogens in Alzheimer disease. Expert Rev Mol Med 13, e30.

[8] MacDonald AB, Miranda JM (1987) Concurrent neocortical borreliosis and Alzheimer's disease. Hum Pathol 18, 759761.

[9] MacDonald AB (1988) Concurrent neocortical borreliosis and Alzheimer's disease: Demonstration of a spirochetal cyst form. Ann N Y Acad Sci 539, 468-470.

[10] Riviere GR, Riviere KH, Smith KS (2002) Molecular and immunological evidence of oral Treponema in the human brain and their association with Alzheimer's disease. Oral Microbiol Immunol 17, 113-118.

[11] Miklossy J (2012) Chronic or late lyme neuroborreliosis: Analysis of evidence compared to chronic or late neurosyphilis. Open Neurol 6, 146-157.

[12] Steiner G (1940) Morphologic appearances of spirochetal reproduction in tissues. Arch Pathol 5, 189-199.

[13] Umemoto T, Namikawa I, Yamamoto M (1984) Colonial morphology of treponemes observed by electron microscopy. Microbiol Immunol 28, 11-22.

[14] Kurtti TJ, Munderloh UG, Johnson RC, Ahlstrand GG (1987) Colony formation and morphology in Borrelia burgdorferi. J Clin Microbiol 25, 2054-2058.

[15] Miklossy J, Kasas S, Zurn AD, McCall S, Yu S, McGeer PL (2008) Persisting atypical and cystic forms of Borrelia burgdorferi and local inflammation in Lyme neuroborreliosis. J Neuroinflammation 5, 40.

[16] Miklossy J, Kis A, Radenovic A, Miller L, Forro L, Martins R, Reiss K, Darbinian N, Darekar P, Mihaly L, Khalili K (2006) Beta-amyloid deposition and Alzheimer's type changes induced by Borrelia spirochetes. Neurobiol Aging 27, 228-236.

[17] Chang WS1, van de Mortel M, Nielsen L, Nino de Guzman G, Li X, Halverson LJ (2007) Alginate production by Pseudomonas putida creates a hydrated microenvironment and contributes to biofilm architecture and stress tolerance under water-limiting conditions. J Bacteriol 189, 82908299. 
[18] Elasri MO, Miller RV (1999) Study of the response of a biofilm bacterial community to UV radiation. Appl Environ Microbiol 65, 2025-2031.

[19] Matz C1, McDougald D, Moreno AM, Yung PY, Yildiz FH, Kjelleberg S (2005). Biofilm formation and phenotypic variation enhance predation-driven persistence of Vibrio cholerae. Proc Natl Acad Sci U S A 102, 1681916824

[20] Allen HB, Morales D, Jones K, Joshi S (2016) Alzheimer's disease: A novel hypothesis integrating spirochetes, biofilm, and the immune system. J Neuroinfect Dis 7, 1 .

[21] Sapi E, Bastian SL, Mpoy CM, Scott S, Rattelle A, Pabbati N, Poruri A, Burugu D, Theophilus PA, Pham TV, Datar A, Dhaliwal NK, MacDonald A, Rossi MJ, Sinha SK, Luecke DF (2012) Characterization of biofilm formation by Borrelia burgdorferi in vitro. PLoS One 7, e48277.

[22] Sapi E, MacDonald A (2008) Biofilms of Borrelia burgdorferi in chronic cutaneous borreliosis. Am J Clin Pathol 129, 988-989.

[23] Sapi E, Balasubramanian K, Poruri A, Maghsoudlou JS, Socarras KM, Timmaraju AV, Filush KR, Gupta K, Shaikh $\mathrm{S}$, Theophilus PAS, LueckeDF, MacDonald A, Zelger B (2016) Evidence of in vivo existence of Borrelia biofilm in borrelial lymphocytomas Eur J Microbiol Immnunol 6, 9-24.

[24] Jacovides CL, Kreft R, Adeli B, Hozack B, Ehrlich GD, Parvizi J (2012) Successful identification of pathogens by polymerase chain reaction (PCR)-based electron spray ionization time-of-flight mass spectrometry (ESI-TOF-MS) in culturenegative periprosthetic joint infection. $J$ Bone Joint Surg Am 94, 2247-2254.

[25] Ohnishi S1, Koide A, Koide S (2000) Solution conformation and amyloid-like fibril formation of a polar peptide derived from a beta-hairpin in the OspA single-layer beta-sheet. J Mol Biol 301, 477-89.

[26] Ohnishi S1, Koide A, Koide S (2001) The roles of turn formation and cross-strand interactions in fibrillization of peptides derived from the OspA single-layer beta-sheet. Protein Sci 10, 2083-2092.

[27] Chapman MR1, Robinson LS, Pinkner JS, Roth R, Heuser J, Hammar M, Normark S, Hultgren SJ (2002) Role of Escherichia coli curli operons in directing amyloid fiber formation. Science 295, 851-855.

[28] Wang X, Hammer ND, Chapman MR (2008) The molecular basis of functional bacterial amyloid polymerization and nucleation. J Biol Chem 283, 21530-21539.

[29] Otzen D, Nielsen PH (2008) We find them here, we find them there: Functional bacterial amyloid. Cell Mol Life Sci 65, 910-927.

[30] Larsen P, Nielsen JL, Dueholm MS, Wetzel R, Otzen D, Nielsen PH (2007) Amyloid adhesins are abundant in natural biofilms. Environ Microbiol 9, 3077-3090.

[31] Jordal PB1, Dueholm MS, Larsen P, Petersen SV, Enghild JJ, Christiansen G, Højrup P, Nielsen PH, Otzen DE (2009) Widespread abundance of functional bacterial amyloid in Mycolata and other Gram-positive bacteria. Appl Environ Microbiol 75, 4101-4110.

[32] Miklossy J, Gern L, Darekar P, Janzer RC, Loos H (1995) Senile plaques, neurofibrillary tangles and neuropil threads contain DNA? J Spirochetal Tick-borne Dis 2, 1-5.

[33] Braak H, Braak E, Bohl J (1993) Staging of Alzheimerrelated cortical destruction. Eur Neurol 33, 403440.

[34] Khachaturian ZS (1985) Diagnosis of Alzheimer's disease. Arch Neurol 42, 1097-1105.
[35] Mirra SS, Hart MN, Terry RD (1993) Making the diagnosis of Alzheimer's disease. Arch Pathol Lab Med 113, 132-144.

[36] Newell KL, Hyman BT, Growdon JH, Hedley-Whyte ET (1999) Application of the National Institute of Aging (NIA)Reagan Institute criteria for the neuropathological diagnosis of Alzheimer disease. J Neuropathol Exp Neurol 58, 11471155.

[37] Bolle L, Maurer B, Janzer RC (1992) A modified HortegaGlobus stain is superior to Bielschowsky and Bodian stains for demonstrating neuritic plaques. Biotech Histochem 67, 82-87.

[38] Gallyas F (1971) Silver staining of Alzheimer's neurofibrillary changes by means of physical development. Acta Morphol Acad Sci Hung 19, 1-8.

[39] Miklossy J, Darekar P, Gern L, Janzer RC, Bosman FT (1996) Bacterial peptidoglycan in neuritic plaques in Alzheimer's disease. Alzheimers Res 2, 95-100.

[40] Miklossy J (1998) Chronic inflammation and amyloidogenesis in Alzheimer's disease: Putative role of bacterial peptidoglycan, a potent inflammatory and amyloidogenic factor. Alzheimers Rev 3, 45-51

[41] Miklossy J, Arai T, Guo JP, Klegeris A, Yu S, McGeer EG, McGeer PL (2006) LRRK2 expression in normal and pathological human brain and in human cell lines. J Neuropathol Exp Neurol 65, 953-963.

[42] Miklossy J, Gern L, Darekar P, Janzer RC, Van der, Loos H (1995) Senile plaques, neurofibrillary tangles and neuropil threads contain DNA? J Spirochetal Tick-borne Dis 2, 1-5.

[43] Soscia SJ, Kirby JE, Washicosky KJ, Tucker SM, Ingelsson M, Hyman B, Burton MA, Goldstein LE, Duong S, Tanzi RE, Moir RD (2010) The Alzheimer's disease-associated amyloid beta-protein is an antimicrobial peptide. PLoS One 5, e9505.

[44] Lashuel HA, Hartley D, Petre BM, Walz T, Lansbury PT Jr (2002) Neurodegenerative disease: Amyloid pores from pathogenic mutations. Nature 418, 291.

[45] Gekara NO, Westphal K, Ma B, Rohde M, Groebe L, Weiss $\mathrm{S}$ (2007) The multiple mechanisms of $\mathrm{Ca} 2+$ signalling by listeriolysin $\mathrm{O}$, the cholesterol-dependent cytolysin of Listeria monocytogenes. Cell Microbiol 9, 2008-2021.

[46] Gonzalez MR, Bischofberger M, Pernot L, van der Goot FG, Freche B (2008) Bacterial pore-forming toxins: The (w)hole story? Cell Mol Life Sci 65, 493-507.

[47] Russel WC, Newman C and Williamson DH (1975) A simple cytochemical technique for demonstration of DNA in cells infected with mycoplasmas and viruses. Nature $\mathbf{2 5 3}$, 461-462.

[48] Hilwig I, Gropp A (1972) Staining of constitutive heterochromatin in mammalian chromosomes with a new fluorochrome. Exp Cell Res 75, 122-124.

[49] Hessling JJ, Miller SE and Levy NL (1980) A direct comparison of procedures for the detection of Mycoplasma in tissue culture. J Immunol Meth 38, 315-324.

[50] Hakansson AP, Roche-Hakansson H, Mossberg AK, Svanborg C (2011) Apoptosis-like death in bacteria induced by HAMLET, a human milk lipid-protein complex. PLoS One 6, e17717.

[51] Dwyer DJ1, Camacho DM, Kohanski MA, Callura JM, Collins JJ (2012) Antibiotic-induced bacterial cell death exhibits physiological and biochemical hallmarks of apoptosis. Mol Cell 46, 561-572.

[52] Zheng W, Rasmussen U, Zheng S, Bao X, Chen B, Gao Y, Guan X, Larsson J, Bergman B (2013) Multiple modes of cell death discovered in a prokaryotic (cyanobacterial) endosymbiont. PLoS One 8, e66147. 
[53] Ramesh G, Alvarez AL, Roberts ED, Dennis VA, Lasater BL, Alvarez X, Philipp MT (2003) Pathogenesis of Lyme neuroborreliosis: Borrelia burgdorferi lipoproteins induce both proliferation and apoptosis in rhesus monkey astrocytes. Eur J Immunol 33, 2539-2550.

[54] Ramesh G1, Borda JT, Dufour J, Kaushal D, Ramamoorthy R, Lackner AA, Philipp MT (2008) Interaction of the Lyme disease spirochete Borrelia burgdorferi with brain parenchyma elicits inflammatory mediators from glial cells as well as glial and neuronal apoptosis. Am J Pathol 173, 1415-1427.

[55] Kornhuber HH (1995) Chronic anaerobic cortical infection in Alzheimer's disease: Propionibacterium acnes. Neurol Psych Brain Res 3, 177-182.

[56] Kornhuber HH (1996) Propionibacterium acnes in the cortex of patients with Alzheimer's disease. Eur Arch Psychiatry Clin Neurosci 246, 108-109.

[57] Balin BJ, Gérard HC, Arking EJ, Appelt DM, Branigan PJ, Abrams JT, Whittum-Hudson JA, Hudson AP (1998) Identification and localization of Chlamydia pneumoniae in the Alzheimer's brain. Med Microbiol Immunol 187, 23-42.

[58] Balin BJ, Little CS, Hammond CJ, Appelt DM, WhittumHudson JA, Gérard HC, Hudson AP (2008) Chlamydophila pneumoniae and the etiology of late-onset Alzheimer's disease. J Alzheimers Dis 13, 371-380.

[59] Poole S, Singhrao SK, Kesavalu L, Curtis MA, Crean S (2013) Determining the presence of periodontopathic virulence factors in short-term postmortem Alzheimer's disease brain tissue. J Alzheimers Dis 36, 665-677.

[60] Poole S, Singhrao SK, Chukkapalli S, Rivera M, Velsko I, Kesavalu L, Crean S (2015) Active invasion of porphyromonas gingivalis and infection-induced complement activation in ApoE-/- mice brains. J Alzheimers Dis 43, 67-80.

[61] Kountouras J, Tsolaki M, Gavalas E, Boziki M, Zavos C, Karatzoglou P, Chatzopoulos D, Venizelos I (2006) Relationship between Helicobacter pylori infection and Alzheimer disease. Neurology 66, 938-940.

[62] Little CS, Joyce TA, Hammond CJ, Matta H, Cahn D, Appelt DM, Balin BJ (2014) Detection of bacterial antigens and Alzheimer's disease-like pathology in the central nervous system of BALB/c mice following intranasal infection with a laboratory isolate of Chlamydia pneumoniae. Front Aging Neurosci 5, 304.

[63] Itzhaki RF, Lin WR, Shang D, Wilcock GK, Faragher B, Jamieson GA (1997) Herpes simplex virus type 1 in brain and risk of Alzheimer's disease. Lancet 349, 241-244.

[64] Itzhaki RF, Wozniak MA (2008) Herpes simplex virus type 1 in Alzheimer's disease: The enemy within. J Alzheimers Dis 13, 393-405.

[65] Wozniak MA, Mee AP, Itzhaki RF (2009) Herpes simplex virus type 1 DNA is located within Alzheimer's disease amyloid plaques. J Pathol 217, 131-138. 